\title{
Farklı adeziv sistemlerin dentine makaslama bağlanma dayanımı: in vitro çalışma
}

\author{
Emel Karaman, ${ }^{1}$ Duygu Tuncer, ${ }^{2}$ \\ Ayşe Rüya Yazıcı, ${ }^{3}$ Sevilay Karahan, ${ }^{4}$ Atila Ertan ${ }^{5}$ \\ ${ }^{1}$ Restoratif Diş Tedavisi Anabilim Dalı, Ondokuz Mayıs \\ Üniversitesi Diş Hekimliği Fakültesi, Samsun, ${ }^{2}$ Restoratif Diş \\ Tedavisi Anabilim Dalı, Başkent Üniversitesi Diş Hekimliği \\ Fakültesi, ${ }^{3}$ Restoratif Diş Tedavisi Anabilim Dalı, \\ Hacettepe Üniversitesi Diş Hekimliği Fakültesi, ${ }^{4}$ Biyoistatistik \\ Anabilim Dalı, Hacettepe Üniversitesi Tıp Fakültesi, ${ }^{5}$ Protetik \\ Diș Tedavisi Anabilim Dalı, Hacettepe Üniversitesi \\ Diş Hekimliği Fakültesi, Ankara, Türkiye
}

\section{ÖZET}

AmAÇ: Bu in vitro çalışmanın amacı kendinden pürüzlendirmeli (self-etch) bir adeziv sistem ve kendinden pürüzlendirmeli olarak da kullanılabilen iki farklı üniversal adeziv sistemin dentine makaslama bağlanma dayanım değerlerinin karşılaştırılmasıdır.

GEREÇ VE YönTEM: Bu çalışmada çekilmiş 36 adet çürüksüz insan molar dişi kullanıldı. Dişler akril kalıplara gömüldükten sonra okluzal mine yüzeyleri aşındırıldı, düzgün bir dentin yüzeyi elde etmek için önce $\mathbf{2 0 0}$ grid ve ardından standart smear tabakası elde etmek için $\mathbf{6 0 0}$ grid silikon karbid disklerle su soğutması altında zımparalandı. Elde edilen örnekler, kullanılan adeziv sisteme göre rastgele 3 gruba ayrıldı ( $n=12)$ : Grup 1: Single Bond Universal (üniversal adeziv), Grup 2: All-Bond Universal (üniversal adeziv), grup 3: Clearfil-SE Bond (kendinden pürüzlendirmeli adeziv). Adeziv uygulanmış yüzeylere $2 \mathrm{~mm}$ çapında, $2 \mathrm{~mm}$ yüksekliğinde teflon kalıplar kullanarak kompozit rezin silindirler bağlandı (Tetric N-Ceram). Örnekler 24 saat distile suda bekletildikten sonra kafa hızı 0.5 mm/dk olan Instron üniversal test cihazına yerleştirildi ve makaslama bağlanma dayanımları ölçüldü. Veriler tek yönlü varyans analizi (ANOVA) ve Tukey HSD testleri kullanılarak değerlendirildi. İstatistiksel anlamlılık düzeyi $\mathrm{p}=\mathbf{0 . 0 5}$ olarak kabul edildi.

BULGULAR: Single Bond Universal ile Clearfil SE grubunun makaslama bağlanma dayanım değerleri arasında istatistiksel olarak anlamlı bir fark bulunmadı ( $p>0.05)$. All-Bond Universal grubu diğer gruplara göre istatistiksel olarak daha düşük bağlanma değerleri gösterdi $(p<0.05)$.

Makale gönderiliş tarihi: 02 Aralık 2014; Yayına kabul tarihi: 16 Ocak 2015 *iletişim: Emel Karaman, Ondokuz Mayıs Üniversitesi Diş Hekimliği Fakültesi, Restoratif Diş Tedavisi AD, Samsun, Türkiye;

e-posta: dtemelc@yahoo.com
Sonuç: Single Bond Universal adeziv sistemi kendinden pürüzlendirmeli olarak kullanıldığında, kendinden pürüzlendirmeli adeziv sistemler için altın standart olarak kabul edilen Clearfil SE Bond ile benzer dentine bağlanma değerleri gösterdi.

Anahtar Kelimeler: Dental adezivler; dentin; dentin yapıştırma ajanları

Kaynak Göstermek İçin: Karaman E, Tuncer D, Yazıcı AR, Karahan S, Ertan A. Farklı adeziv sistemlerin dentine makaslama bağlanma dayanımı: in vitro çalışma. Acta Odontol Turc 2015;32(3):112-5.

YAYIN HAKKI: () 2015 Karaman ve ark. Bu eserin yayın hakkı Creative Commons Attribution License ile ruhsatlandırılmıştır. Sınırsız kullanım, dağıtım ve her türlü ortamda çoğaltım, yazarlar ve kaynağın belirtilmesi kaydıyla serbesttir.

[Abstract in English is at the end of the manuscript]

\section{Giriş}

Son yıllarda gerek hastaların estetik restorasyonlara olan ilgi ve taleplerinin artması gerekse daha konservatif kavite preperasyonları uygulanması nedeniyle direkt kompozit rezin materyallerin kullanımı oldukça yaygınlaşmıştır. Kompozit restorasyonların klinik başarısı, uygulanan adeziv sistemin başarısıyla doğrudan ilişkilidir. ${ }^{1}$

Güncel adeziv sistemler pürüzlendirip yıkamalı (etch\&rinse) ve kendinden pürüzlendirmeli (self-etch) adeziv sistemler olarak ikiye ayrılmaktadır. Ayrıca uygulama aşamalarına göre bu sistemler tek aşamalı, iki ve üç aşamalı sistemler olarak da alt gruplara ayrılmaktadırlar. ${ }^{2}$

Pürüzlendirip yıkamalı sistemlerin başlıca dezavantajı dentinin nemlilik düzeyine olan duyarlııklarıdır. Dentinin aşırı nemli olduğu durumlarda, rezin monomerler kollajen fibriller arasını tam olarak dolduramaz ve bağlantı ara yüzeyinde demineralize bölgeler kalır. ${ }^{3}$ Dentin dokusunun fazlaca kurutulduğu durumlarda ise kollajen fibriller çökelir ve monomer tarafından penetre olamaz, rezin taglar yeterince oluşamadığından bu durum bağlantının zayıflamasına ve hastanın post-operatif hassasiyet duymasına neden olur. ${ }^{4}$ Pürüzlendirip yıkamalı sistemlerde karşılaşılan bu sorunları önlemek ve teknik hassasiyeti azaltmak için geliştirilen kendinden pürüzlendirmeli sistemler ise dentin yüzeyini pürüzlendirip yı- 
kamalı sistemler kadar derin demineralize edememektedir. ${ }^{1}$ Ayrıca mine dokusunu da fosforik asit kadar pürüzlendiremediklerinden, mine dokusuyla kurdukları zayıf bağlantı sonucu uygulanan restorasyonlarda mikrosızıntılar görülebilmektedir. ${ }^{5}$ Mine dokusuyla olan bu zayıf bağlantıyı güçlendirebilmek için kendinden pürüzlendirmeli sistemler uygulanmadan önce mine kenarlarının selektif olarak fosforik asit ile pürüzlendirilmesi önerilmektedir; ${ }^{6}$ ancak bu yöntem klinik koşullarda pek pratik ve uygulanabilir bir yöntem değildir.

Geçtiğimiz yıllarda hem pürüzlendirip yıkamalı hem de kendinden pürüzlendirmeli teknikle beraber uygulanabilecek, 'üniversal' ya da 'multi-mod' olarak adlandırıIan yeni bir tek aşamalı kendinden pürüzlendirmeli adeziv sistem grubu piyasaya sürülmüştür. ${ }^{7}$ Bu yeni sistem sayesinde hekim, tek bir adeziv ile, hazırladığı kaviteye ve uygulayacağı restorasyona en uygun olan adeziv uygulamasına karar verme şansına sahip olmaktadır.

$\mathrm{Bu}$ in vitro çalışmanın amacı, diş hekimliğinde altın standart kabul edilen kendinden pürüzlendirmeli bir adeziv sistem ile kendinden pürüzlendirmeli teknikle de uygulanabilen iki farklı üniversal adeziv sistemin dentine makaslama bağlanma dayanım değerlerini karşılaştırmaktır.

\section{Gereç Ve Yöntem}

Bu çalışmada, son altı ay içinde çekilmiş 36 adet çürüksüz insan molar dişi kullanıldı. Çürüklü, restorasyonlu ya da gözlenebilen defekti olan dişler çalışmaya dahil edildi. Dişlerin üzerindeki eklentiler periodontal küret yardımıyla uzaklaştırıldı ve dişler, mine-sement sınırının $2 \mathrm{~mm}$ apikalinden akril kalıplara gömüldü. Dişlerin okluzal yüzeylerindeki mine dokusu uzaklaştırılıp, düzgün bir dentin yüzeyi elde etmek için yüzeyleri su soğutması altında 200 grid silikon karbid disklerle aşındırıldı. Elde edilen dentin yüzeylerinde standart bir smear tabakası sağlayabilmek için tüm örnekler 600 grid silikon karbid disklerle su soğutması altında tekrar zımparalandı. Hazırlanan örnekler rastgele üç gruba ayrıldı $(n=12)$ :
Grup 1: Single Bond Universal (üniversal adeziv; 3M ESPE, St. Paul, MN, ABD) dentin yüzeyine bir mikro fırça ile 20 sn boyunca uygulandı, 5 sn hava ile kurutulduktan sonra LED cihazı ile 10 sn polimerize edildi (Elipar S10, 3M ESPE, St. Paul, MN, ABD).

Grup 2: All-Bond Universal (üniversal adeziv; Bisco Inc, Schaumburg, IL, ABD) dentin yüzeyine bir mikro fırça yardımıyla 10-15 sn süresince iki tabaka olarak uygulandı, 10 sn hava ile kurutulduktan sonra 10 sn ışıkla polimerize edildi.

Grup 3: Clearfil-SE Bond (kendinden pürüzlendirmeli adeziv; Kuraray, Osaka, Japonya) primeri dentin yüzeyine 20 sn uygulandı, 5 sn hava ile uçucu komponentler uzaklaştırıldı ve bonding uygulanıp 10 sn süresince polimerize edildi.

Çalışmada kullanılan adeziv sistemler ve içerikleri Tablo 1'de gösterilmektedir. Üretici firmaların talimatları doğrultusunda hazırlanan adeziv yüzeylere, $2 \mathrm{~mm}$ çapında ve $2 \mathrm{~mm}$ yüksekliğinde teflon kalıplar yardımıyla kompozit rezin silindirler yerleştirildi (Tetric N-Ceram, Ivoclar Vivadent, Schaan, Lihtenştayn)ve 20 sn süresince polimerize edildi. Örnekler 24 saat distile suda bekletildikten sonra Instron üniversal test cihazında (Lloyd Instruments, Leicester, Ingiltere) $0.5 \mathrm{~mm} / \mathrm{dk}$ kafa hızıyla dentin-kompozit ara yüzüne, bağlantı kopuncaya kadar kuvvet uygulandı. Newton cinsinden elde edilen veriler MPa'ya çevrilerek tek yönlü varyans analizi (ANOVA) kullanılarak değerlendirildi $(p<0.05)$. Anlamlı farklılığın hangi gruplar arasında olduğunu test etmek için Tukey HSD ikili karşılaştırma testi yapıldı.

\section{BULGULAR}

Tablo 2'de çalışma gruplarının ortalama makaslama bağlanma dayanım değerleri ve standart sapmaları gösterilmektedir. Gruplar arasında en yüksek bağlanma dayanımı Single Bond Universal uygulanan Grup 1'de gözlenirken, en düşük değerler All-Bond Universal uygulanan Grup 2'de gözlendi. Single Bond Universal ve Clearfil SE Bond uygulanan grupların makaslama bağlanma dayanım değerleri arasında istatistiksel olarak anlamlı bir fark bulunamadı ( $p>0.05)$. All-Bond Universal

Tablo 1. Çalışmada kullanılan adeziv sistemler

\begin{tabular}{lcc}
\hline Adeziv & İçerik & Üretici \\
\hline $\begin{array}{l}\text { Single Bond Universal } \\
\text { (üniversal adeziv) }\end{array}$ & $\begin{array}{l}\text { MDP fosfat monomer, bis-GMA, HEMA, DMA, metakrilat-modifiye } \\
\text { polialkenoik asit kopolimeri, doldurucu, etanol, su, inisiyatörler, silan }\end{array}$ & 3M ESPE, St. Paul, MN, ABD \\
$\begin{array}{l}\text { All Bond Universal } \\
\text { (üniversal adeziv) }\end{array}$ & MDP, bis-GMA, HEMA, etanol, su, inisiyatörler & Bisco Inc, Schaumburg, IL, ABD \\
$\begin{array}{ll}\text { Clearfil SE Bond } \\
\text { (kendinden pürüzlendirmeli adeziv) }\end{array}$ & $\begin{array}{l}\text { Primer: MDP, HEMA,Dimetakrilatlar, Di-kanforokinon, } \\
\text { N,N-Dietanol-p-toluidin, su }\end{array}$ & Kuraray, Osaka, Japonya \\
& $\begin{array}{l}\text { Bond: MDP, BisGMA, HEMA, Dimetakrilatlar, Di-kanforokinon, } \\
\text { N,N-Dietanol-p-toluidin,silanize kolloidal silika }\end{array}$ & Bond: 5U0060 \\
\hline
\end{tabular}


Tablo 2. Grupların ortalama makaslama bağlanma dayanımı ve standart sapma değerleri (MPa $\pm S S)$

\begin{tabular}{lcc}
\hline Gruplar & $\mathbf{n}$ & Ortalama \pm SS \\
\hline Grup 1: Single Bond Universal & 12 & $17.51 \pm 6.01^{\mathrm{A}}$ \\
Grup 2: All-Bond Universal & 12 & $10.45 \pm 3.62^{\mathrm{B}}$ \\
Grup 3: Clearfil SE Bond & 12 & $16.29 \pm 5.50^{\mathrm{A}}$
\end{tabular}

Farklı üst simge harfler istatistiksel olarak anlamlı farkllıkları göstermektedir $(p<0.05)$

uygulanan grup diğer gruplara göre istatistiksel olarak daha düşük bağlanma dayanım değerleri gösterdi $(p<0.05)$.

\section{TARTIŞMA}

Dentin dokusunun nemli ve karmaşık yapısı nedeniyle dentin dokusuna bağlanma mine dokusuna bağlanmaya göre daha zordur ve adeziv uygulaması daha fazla dikkat gerektirir. ${ }^{8}$ Ayrıca, smear tabakasının yapısı da kullanılan adeziv sisteme ve sistemin pH'sına göre farklılık da göstermektedir. ${ }^{9}$ Üniversal adeziv sistemler dental marketlerde yer alan en yeni adeziv sistemlerdir. Tek aşamalı kendinden pürüzlendirmeli adezivlerde olduğu gibi 'All-inone' konsepti ile tasarlanmışlardır; ancak çok amaçlı kullanımları mümkün olduğundan, fosforik asitle beraber veya sadece kendinden pürüzlendirmeli olarak kullanılabilirler. ${ }^{10}$

Clearfil SE Bond piyasadaki tüm kendinden pürüzlendirmeli adeziv sistemler içerisinde altın standart olarak kabul edilen üründür. ${ }^{5}$ Clearfil SE Bond'un mine dokusuna bağlanma kuvvetinin pürüzlendirip yıkamalı sistemlerle benzer, dentine bağlanma değerlerinin ise pürüzlendirip yıkamalı sistemlere göre daha yüksek olduğu bildirilmiştir. ${ }^{11} \mathrm{Bu}$ in vitro çalışma diş hekimliği pratiğinde kullanımı henüz çok yeni olan üniversal adeziv sistemlerin dentin dokusuna olan makaslama bağlanma dayanımını, altın standart olarak kabul edilen bir kendinden pürüzlendirmeli adeziv sistem (Clearfil SE Bond) ile karşılaştırmak üzere gerçekleştirilmiştir.

Makaslama bağlanma dayanım testleri, dental materyal ve tekniklerin in vitro koşullarda değerlendirilmesinde sıklıkla tercih edilen yöntemlerden biridir. ${ }^{12} \mathrm{Bu}$ çalışmada da pratik ve yaygın bir yöntem olduğundan makaslama bağlanma dayanım testi tercih edilmiştir. Hazırlanan örneklere 24 saat sonunda teste tabi tutulduklarından, elde edilen sonuçlar 'immediate bond strength' olarak nitelendirilmektedir.

Çalışmamızda pürüzlendirip yıkamalı ve kendinden pürüzlendirmeli olarak kullanılabilen iki farklı üniversal adeziv ve kendinden pürüzlendirmeli bir adeziv olan Clearfil SE Bond'un dentine makaslama bağlanma dayanımı değerleri arasında istatistiksel olarak anlamlı düzeyde farklılıklar görülmüştür. Literatürde benzer adeziv sistemler kullanılarak yapılmış çalışmalar incelendiğinde çe- lişkili sonuçlarla karşılaşılmaktadır. Perdigao ve ark. ${ }^{13}$ Single Bond Universal adezivin dentin dokusuna, Clearfil SE Bond'dan daha iyi bağlandığını bildirirken, Munoz ve ark. ${ }^{14}$ ise Clearfil SE Bond kullanılan grupta daha yüksek bağlanma değerleri elde ettiklerini bildirmişlerdir. Barutcigil ve ark. ${ }^{15}$ yaptıkları çalışmada kendinden pürüzlendirmeli olarak kullanılan üniversal adeziv sistemler (Single Bond Universal, All-Bond Universal) ve Clearfil SE Bond arasında dentine makaslama bağlanma dayanımı değerlerinde farklııı gözlemlememişlerdir. Yine başka bir çalışmada, kontrol grubu olarak kullanılan Clearfil SE Bond grubunun mikrogerilim bağlanma kuvveti değerleri test edilen Single Bond Universal ve All-Bond Universal'a göre daha yüksek bulunmuştur. ${ }^{14}$ Bizim çaIışmamızda da olduğu gibi, All-Bond Universal, diğer bütün adeziv sistemlere göre en düşük bağlanma değerlerini göstermiştir. ${ }^{14}$ Tüm bu çalışmalarda elde edilen farklı sonuçlar uygulanan yöntemlerin, kullanılan dişlerin ya da çalışma tasarımlarının faklı olmasıyla ilgili olabilir.

Bu çalışmada kullanılan üç adeziv sistem de 10-metakriloloksidesil dihidrojen fosfat (MDP) monomer içermeleri nedeniyle mine ve dentin dokusuna kimyasal olarak bağlanabilmektedirler. ${ }^{16,17} \mathrm{Bu}$ monomerin hidroksiapatit ile bağlanmasıyla bağlantı ara yüzünde mekanik direncin arttığı ve dayanıklılığın en yüksek seviyeye ulaşmasını sağlayan bir nanotabaka meydana geldiği bildirilmiştir. ${ }^{16}$ Kullanılan diğer adezivlerden farklı olarak Single Bond Universal adeziv sistemin içeriğinde polialkenoik asit kopolimeri bulunmaktadır. Polialkenoik asit kopolimeri ilk kez bir cam iyonomer siman olan Vitrebond (3M ESPE) içerisinde kullanıldığından, Vitrebond kopolimeri olarak da adlandırımaktadır. Kendinden pürüzlendirmeli adezivlerin bağlanma mekanizmasında bu kopolimer ve hidroksiapatit arasında meydana gelen kimyasal bağlanma kritik bir rol oynamaktadır. ${ }^{18}$ Polialkenoik asit kopolimeri içindeki karboksil gruplarının $\% 50$ 'den fazlasının hidroksiapatit ile bağlanbildiği, fosfat iyonları ile yer değiştirerek kalsiyum ile iyonik bağlar kurabildiği bildirilmiştir. ${ }^{19}$ Single Bond Universal kullanılan grupta gözlenen en yüksek bağlanma değerleri bu adeziv sistemin içeriğinde polialkenoik asit kopolimeri bulunmasıyla ilişkili olabileceğini düşünmekteyiz.

\section{Sonuç}

Bu çalışmanın bulguları ışığında, Single Bond Universal adezivin kendinden pürüzlendirmeli sistem olarak kullanıldığında, dentine olan bağlanma değerlerinin, günümüzde altın standart olarak kabul edilen Clearfil SE Bond ile benzer olduğu sonucuna varılmıştır. Ancak in vitro çalışmalar ağız içi koşulları tam olarak taklit edemeyeceğinden, bu çalışmanın sonuçlarının desteklenebilmesi ve bu adeziv sistemlerin uzun dönem performanslarının değerlendirilebilmesi amacıyla in vivo çalışmalara mutlaka intiyaç vardır. 


\section{TEŞEKKür VE ANMA}

Bu çalışma daha önce 27-28 Ekim 2014 tarihlerinde İstanbul'da gerçekleştirilen Restoratif Diş Hekimliği Derneği, 19. Uluslar arası Bilimsel Kongresi'nde poster olarak sunulmuştur.

Çıkar çatışması: Yazarlar bu çalışmayla ilgili herhangi bir çıkar çatışmalarının bulunmadığını bildirmişlerdir.

\section{KAYNAKLAR}

1. Breschi L, Mazzoni A, Ruggeri A, Cadenaro M, Di Lenarda R, De Stefano Dorigo E. Dental adhesion review: aging and stability of the bonded interface. Dent Mater 2008;24:90-101.

2. De Munck J, Van Landuyt K, Peumans M, Poitevin A, Lambrechts $P$, Braem $M$, et al. A critical review of the durability of adhesion to tooth tissue: methods and results. J Dent Res 2005;84:118-32.

3. Pioch T, Staehle HJ, Wurst M, Duschner H, Dörfer C. The nanoleakage phenomenon: influence of moist vs dry bonding. J Adhes Dent 2002;4:23-30.

4. Hashimoto $M$, Ohno $H$, Kaga M, Endo K, Sano $H$, Oguchi $H$. In vivo degradation of resin-dentin bonds in humans over 1 to 3 years. J Dent Res 2000;79:1385-91.

5. Peumans M, De Munck J, Van Landuyt KL, Poitevin A, Lambrechts $P$, Van Meerbeek B. Eight-year clinical evaluation of a 2-step self-etch adhesive with and without selective enamel etching. Dent Mater 2010;26:1176-84.

6. Erickson RL, Barkmeier WW, Latta MA. The role of etching in bonding to enamel: a comparison of self-etching and etch-and-rinse adhesive systems. Dent Mater 2009;25:1459-67.

7. Hanabusa M, Mine A, Kuboki T, Momoi Y, Van Ende A, Van Meerbeek $B$, et al. Bonding effectiveness of a new 'multi-mode' adhesive to enamel and dentine. J Dent 2012;40:475-84.

8. Itthagarun A, Tay FR. Self-contamination of deep dentin by dentin fluid. Am J Dent 2000;13:195-200.

9. Shinoda Y, Nakajima M, Hosaka K, Otsuki M, Foxton RM, Tagami J. Effect of smear layer characteristics on dentin bonding durability of HEMA-free and HEMA-containing one-step self-etch adhesives. Dent Mater J 2011;30:501-10.

10. Wagner A, Wendler M, Petschelt A, Belli R, Lohbauer U. Bonding performance of üniversal adhesives in different etching modes. J Dent 2014;42:800-7.

11. Kubo S, Yokota H, Sata Y, Hayashi Y. Microleakage of self-etching primers after thermal and flexural load cycling. Am J Dent 2001;14:1639.

12. Moll K, Fritzenschaft $A$, Haller $B$. In vitro comparison of dentin bonding systems: effect of testing method and operator. Quintessence Int 2004;35:845-52.

13. Perdigão J, Sezinando A, Monteiro PC. Laboratory bonding ability of a multi-purpose dentin adhesive. Am J Dent 2012;25:153-8.

14. Munoz MA, Luque I, Hass V, Reis A, Loguercio AD, Bombarda NH. Immediate bonding properties of universal adhesives to dentine. J Dent 2013;41:404-11.

15. Barutcigil Ç, Barutcigil K, Kürklü D, Harorlı OT. Güncel Dentin Bağlayıcı Ajanların ve Uygulama Yöntemlerinin Makaslama Bağlanma Dayanımlarının Karşılaştırılması. İnönü Üniversitesi Sağlık Bilimleri Dergisi 2013;2:27-32.

16. Yoshida Y, Yoshihara K, Nagaoka N, Hayakawa S, Torii Y, Ogawa $\mathrm{T}$, et al. Self-assembled Nano-layering at the Adhesive interface. J Dent Res 2012;91:376-81.
17. Waidyasekera K, Nikaido T, Weerasinghe DS, Ichinose S, Tagami J. Reinforcement of dentin in self-etch adhesive technology: a new concept. J Dent 2009;37:604-9.

18. Yoshida Y, Van Meerbeek B, Nakayama Y, Snauwaert J, Hellemans $\mathrm{L}$, Lambrechts $\mathrm{P}$, et al. Evidence of chemical bonding at biomaterialhard tissue interfaces. J Dent Res 2000;79:709-14.

19. Lin A, Mclntyre NS, Davidson RD. Studies on the adhesion of glassionomer cements to dentin. J Dent Res 1992;71:1836-41.

\section{Shear bond strength of different adhesive systems to dentin: in vitro study}

\begin{abstract}
OвJECTIVE: The aim of this in vitro study was to compare the shear bond strengths of a self-etch adhesive with two different multi-mode adhesive systems which can also be used as self-etch adhesive.
\end{abstract}

Materials AND Method: In this study, 36 extracted human molar teeth were used. The teeth were embedded in acrylic molds. In order to obtain flat dentin surfaces, the occlusal enamel surfaces of the teeth were abraded. Then, to obtain standard smear layer, surfaces were polished with 200 and 600 grid sandpaper under running water. The samples were randomly divided into 3 groups $(n=12)$ according to the adhesive systems: Group 1: Single Bond Universal (universal adhesive), Group 2: All Bond Universal (universal adhesive), Group 3: Clearfil SE Bond (self-etch adhesive). Composite resin cylinders (radius $=2 \mathrm{~mm}$, height $=2$ $\mathrm{mm}$; Tetric N Ceram) were bonded to the adhesive applied surfaces by using teflon molds. After storing in distilled water for $\mathbf{2 4} \mathrm{h}$, a shear load was applied to the samples using an Instron universal test machine at a cross-head speed of $0.5 \mathrm{~mm} / \mathrm{min}$ until failure occurred. Shear bond strength values were calculated. Data were analyzed by using One-Way Variance analysis (ANOVA) and Tukey HSD tests. The level of statistical significance was set to $\mathrm{p}=0.05$.

RESULTS: The shear bond strength values of Single Bond Universal and Clearfil SE groups were not significantly different $(p>0.05)$. The All Bond Universal group showed significantly lower bond strength values than the other groups $(p<0.05)$.

Conclusion: When Single Bond Universal was used as a self-etch system, it showed similar shear bond strength to Clearfil SE Bond, an adhesive accepted as the gold standard among self-etch adhesive systems.

KEYWORDS: Dental adhesives; dentin; dentin-bonding agents 